\title{
Article \\ Environmental Impacts and Immobilization Mechanisms of Cadmium, Lead and Zinc in Geotechnical Composites Made from Contaminated Soil and Paper-Ash
}

\author{
Marija Đurić 1,3 ${ }^{\mathbb{D}}$, Primož Oprčkal ${ }^{1}$, Vesna Zalar Serjun ${ }^{1} \mathbb{D}$, Alenka Mauko Pranjić ${ }^{1} \mathbb{D}$, Janez Ščančar ${ }^{2,3}{ }^{\mathbb{D}}$, \\ Radmila Milačič ${ }^{2,3, * \mathbb{D}}$ and Ana Mladenovič ${ }^{1, *}$
}

1 Department of Materials, Slovenian National Building and Civil Engineering Institute, Dimičeva ulica 12, 1000 Ljubljana, Slovenia; marija.djuric@zag.si (M.Đ.); primoz.oprckal@zag.si (P.O.); vesna.zalar@zag.si (V.Z.S.); alenka.mauko@zag.si (A.M.P.)

2 Department of Environmental Sciences, Jožef Stefan Institute, Jamova 39, 1000 Ljubljana, Slovenia; janez.scancar@ijs.si

3 Jožef Stefan International Postgraduate School, Jamova 39, 1000 Ljubljana, Slovenia

* Correspondence: radmila.milacic@ijs.si (R.M.); ana.mladenovic@zag.si (A.M.); Tel.: +386-1-477-3560 (R.M.); +386-1-280-4394 (A.M.)

check for updates

Citation: Đurić, M.; Oprčkal, P.; Zalar Serjun, V.; Pranjić, A.M.;

Ščančar, J.; Milačič, R.; Mladenovič, A. Environmental Impacts and Immobilization Mechanisms of Cadmium, Lead and Zinc in Geotechnical Composites Made from Contaminated Soil and Paper-Ash. Appl. Sci. 2021, 11, 11822. https:// doi.org/10.3390/app112411822

Academic Editor: Fulvia Chiampo

Received: 17 November 2021

Accepted: 7 December 2021

Published: 13 December 2021

Publisher's Note: MDPI stays neutral with regard to jurisdictional claims in published maps and institutional affiliations.

Copyright: (c) 2021 by the authors. Licensee MDPI, Basel, Switzerland. This article is an open access article distributed under the terms and conditions of the Creative Commons Attribution (CC BY) license (https:/ / creativecommons.org/licenses/by/ $4.0 /)$.

\begin{abstract}
Paper-ash is used for remediation of heavily contaminated soils with metals, but remediation efficiency after longer periods has not been reported. To gain insights into the mechanisms of immobilization of cadmium $(\mathrm{Cd})$, lead $(\mathrm{Pb})$, and znic $(\mathrm{Zn})$, a study was performed in the laboratory experiment in uncontaminated, artificially contaminated, and remediated soils, and these soils treated with sulfate, to mimic conditions in contaminated soil from zinc smelter site. Remediation was performed by mixing contaminated soil with paper-ash to immobilize $\mathrm{Cd}, \mathrm{Pb}$, and $\mathrm{Zn}$ in the geotechnical composite. Partitioning of $\mathrm{Cd}, \mathrm{Pb}$, and $\mathrm{Zn}$ was studied over one year in seven-time intervals applying the sequential extraction procedure and complementary $\mathrm{X}$-ray diffraction analyses. This methodological approach enabled us to follow the redistribution of $\mathrm{Cd}, \mathrm{Pb}$, and $\mathrm{Zn}$ over time, thus, to studying immobilization mechanisms and assessing the remediation efficiency and stability of newly formed mineral phases. $\mathrm{Cd}, \mathrm{Pb}$, and $\mathrm{Zn}$ were effectively immobilized by precipitation of insoluble hydroxides after the addition of paper-ash and by the carbonization process in insoluble carbonate minerals. After remediation, $\mathrm{Cd}, \mathrm{Pb}$, and $\mathrm{Zn}$ concentrations in the water-soluble fraction were well below the limiting values for inertness: C d by 100 times, Pb by 125 times, and $\mathrm{Zn}$ by 10 times. Sulfate treatment did not influence the remediation efficiency. Experimental data confirmed the high remediation efficiency and stability of insoluble $\mathrm{Cd}, \mathrm{Pb}$, and $\mathrm{Zn}$ mineral phases in geotechnical composites.
\end{abstract}

Keywords: cadmium; lead; zinc; contaminated soil; paper ash; immobilization mechanisms

\section{Introduction}

The growth of the human population and activities, like industrialization, mining, and the intensification of agriculture, have made soil pollution one of the world's most serious environmental problems. It could negatively influence agricultural production, threaten food safety, and endanger the health of natural ecosystems and lifeforms. There are over 10 million major soil-contaminated areas around the world, of which 50\% are contaminated by heavy metals and metalloids [1,2]. The Food and Agriculture Organization of the United Nations (FAO) classified the prevention of soil pollution as a top priority worldwide [3].

Heavy metals and metalloids are of great concern due to their potential toxicity, persistency and since they cannot be degraded. These elements are frequently released into terrestrial environmental compartments with anthropogenic emissions in the form of easily soluble, highly mobile chemical species. These are bioavailable and can contaminate both surface and ground waters $[4,5]$. Significant efforts are being made to remediate 
soil-contaminated sites in Europe [6] and around the world [1]. The crucial role of the remediation of contaminated soils is to reduce the mobility of metals and metalloids in the soil using different immobilizing agents. The process of immobilization occurs through adsorption, complexation, and precipitation reaction [7-9] and redistributes the heavy metals from the soil solution to the less-soluble soil fractions, while their total concentrations remain unchanged. The most commonly used amendments for in situ immobilization include cement [10], clay minerals [11], zeolites [12], biochar [13], phosphates [14], humic substances [15], and various industrial by-products like fly ash [16], paper-ash $[17,18]$ and red mud from aluminum production [18]. Among the immobilization processes, a carbonation treatment under alkaline conditions ( $\mathrm{pH}$ 10-10.5) was shown to effectively reduce the mobility of lead $(\mathrm{Pb})$, zinc $(\mathrm{Zn})$, chromium $(\mathrm{Cr})$, copper $(\mathrm{Cu})$, and molybdenum (Mo) in residues from the combustion of municipal solid waste [19]. When immobilization techniques are applied for remediation, the stability of the immobilized metals must be evaluated. For this purpose, it is necessary to know to which mineral phases the contaminants were redistributed after the remediation.

To evaluate the immobilization efficiency, leaching tests using demineralized water as the extracting solution (liquid-to-solid ratio of $10 \mathrm{~L} / \mathrm{kg}$ ) [20] or single-extraction procedures were often applied [21]. Sequential extraction procedures in combination with element-specific detectors, e.g., inductively coupled plasma mass spectrometry (ICP-MS), provide useful information about the partitioning of metals in soils, sediments, and waste materials [22,23]. They involve different extractants, which are applied successively to the solid material to selectively leach the particular chemical forms of the metals from the samples analyzed. Each extractant is chemically more rigorous than the previous one [21]. Many of these extraction procedures are based on the method developed by Tessier et al., which includes the five-step sequential extraction [24]. With slight modifications, Tessier's scheme was used in the evaluation of the environmental impacts of waste materials and contaminated sediments and soils $[25,26]$. In addition, frequently used were the BCR three-step sequential extraction procedures $[27,28]$. The BCR sequential extraction scheme, in which $0.11 \mathrm{M}$ acetic acid is used to extract the exchangeable fraction, is not appropriate for highly alkaline sample matrices. After the addition of acetic acid, the $\mathrm{pH}$ of the sample is reduced, leading to apparently greater mobility of most metals, which does not reflect their mobility in stabilized chemical forms in highly alkaline conditions [29].

Sequential extraction procedures can also provide essential information on a metal's mobility after remediation. Janoš et al. [30] studied the leachability of $\mathrm{Cd}, \mathrm{Pb}, \mathrm{Zn}$, and $\mathrm{Cu}$ from contaminated soils and soils amended with different additives. Three months after the soils' treatments, the BCR extraction procedure was applied to study the partitioning of the metals after the remediation. The results revealed that $\mathrm{Cd}$ and $\mathrm{Pb}$ mobility was effectively reduced after the addition of potassium humate, while $\mathrm{Cu}$ mobility was reduced after the addition of zeolite or fly ash. The addition of amendments did not influence the mobility of $\mathrm{Zn}$. Ashrafi et al. [31] investigated the efficiency of the immobilization of $\mathrm{Pb}, \mathrm{Cd}$, and $\mathrm{Zn}$ in an artificially contaminated soil, using eggshell and banana-stem amendments. Three months after the soil amendments, Tessier's sequential extraction procedure was applied. The results showed that in eggshell-treated soil, $\mathrm{Pb}, \mathrm{Cd}$, and $\mathrm{Zn}$ were transferred from the easily mobile to sparingly soluble soil fractions, while the banana-stem amendment reduced the exchangeable Cd content and increased its residual form in the soil.

Useful information about the stabilization of metals in different mineral phases after treatments with immobilizing agents can be obtained with transmission electron microscopy (TEM), scanning electron microscope (SEM), and powder X-ray diffraction (XRD) $[18,32,33]$. XRD, SEM, and TEM, in combination with sequential extraction procedures, provide complementary data on the distribution of metals in different mineral phases of the contaminated soils, delivering valuable information about alternatives for the remediation of contaminated sites [34]. Nejad et al. [35] investigated the potential of biochars, red mud, and steel slag for the in situ stabilization of $\mathrm{Cd}, \mathrm{Cu}, \mathrm{Pb}$, and $\mathrm{Zn}$ in soil. The results of the sequential extraction analysis demonstrated that the application 
of biochars increases the metal fractions associated with carbonate and organic matter. The application of red mud and steel slag substantially increased the soil $\mathrm{pH}$, leading to metal precipitation and their transfer from the easily soluble forms to the sparingly soluble fractions associated with $\mathrm{Fe} / \mathrm{Mn}$ oxides and alumo-silicates. The latter findings were supported by the XRD analyses. By the above-reported approaches using sequential extraction procedures and/or their combination with XRD or microscopic techniques, it was possible only to evaluate the short-term efficiency of remediation (after three months). Since only one experiment was performed after three months, it was not possible to follow the mechanisms of immobilization of contaminants during the remediation process, nor to evaluate the efficiency of remediation and stability of the formed mineral phases after a longer period of time.

In Slovenia, the area around the abandoned zinc smelter "Old Zinc-works" site in the town Celje is heavily polluted with $\mathrm{Cd}, \mathrm{Pb}$, and $\mathrm{Zn}$. Among the anions, sulfate is present as a contaminant. One of the promising methods for remediation is an in situ immobilization with paper-ash, which is locally available recycled material. The highly alkaline paper-ash ( $\mathrm{pH} 12$ ) is mixed with polluted soil, forming a geotechnical composite. The results reveal that the $\mathrm{Cd}, \mathrm{Pb}$, and $\mathrm{Zn}$ in a highly mobile water-soluble fraction are being significantly reduced after immobilization [18]. However, there is a lack of data on the stability of geotechnical composites and a lack of knowledge about which soil phases the $\mathrm{Cd}, \mathrm{Pb}$, and Zn were transferred to after the remediation.

In the present work, an investigation based on modified Tessier's sequential extraction procedure in combination with XRD analyses was performed (i) to gain a deeper insight into the mechanisms of immobilization by determining with which mineral phases $\mathrm{Cd}$, $\mathrm{Pb}$, and $\mathrm{Zn}$ are associated in different time intervals in the soil after the remediation with paper-ash, (ii) to assess the stability of newly formed mineral phases of $\mathrm{Cd}, \mathrm{Pb}$ and $\mathrm{Zn}$ after remediation, and (iii) to evaluate the environmental impacts of soil remediation. For this purpose, natural soil with a grain size in the range of silt and clay and the same soil with the addition of sulfate was artificially contaminated with $\mathrm{Cd}, \mathrm{Pb}$, and $\mathrm{Zn}$ and remediated by the addition of paper-ash. Sulfate was added in a similar concentration as found at the "Old Zinc-woks" site to evaluate whether this contaminant has any influence on the mechanisms and efficiency of remediation by paper-ash. To achieve the above-mentioned objectives and to obtain data enabling the study of $\mathrm{Cd}, \mathrm{Pb}$, and $\mathrm{Zn}$ immobilization mechanisms, a sequential extraction procedure, and XRD analyses were performed over one year 7, 28, 56, 90,120 , and 365 days after the remediation.

\section{Materials and Methods}

\subsection{Reagents and Materials}

For the preparation of the samples and the standard solutions, Merck (Darmstadt, Germany) suprapure acids and Milli-Q water $(18.2 \mathrm{M} \Omega \mathrm{cm})$ were obtained from DirectQ 5 Ultrapure water system (Millipore, Watertown, MA, USA) were used. A stock IV CertiPUR ICP Multi Element Standard Solution containing $1000 \mathrm{mg} / \mathrm{L} \pm 10 \mathrm{mg} / \mathrm{L}$ element concentrations in $1 \mathrm{M}$ HNO3 (Merck, Darmstadt, Germany) was used for the preparation of working standard solutions for the ICP-MS determinations. All the other reagents were of analytical reagent grade.

Cadmium nitrate tetrahydrate $\left(\left(\mathrm{Cd}\left(\mathrm{NO}_{3}\right)_{2} 4 \mathrm{H}_{2} \mathrm{O}\right)\right.$, lead nitrate $\left(\mathrm{Pb}\left(\mathrm{NO}_{3}\right)_{2}\right)$, zinc nitrate hexahydrate $\left(\left(\mathrm{Zn}\left(\mathrm{NO}_{3}\right)_{2} 6 \mathrm{H}_{2} \mathrm{O}\right)\right.$, calcium sulfate dehydrate $\left(\mathrm{CaSO}_{4} 2 \mathrm{H}_{2} \mathrm{O}\right)$, magnesium chloride $\left(\mathrm{MgCl}_{2}\right)$, sodium acetate $\left(\mathrm{CH}_{3} \mathrm{COONa}\right)$, hydroxylamine hydrochloride $\left(\mathrm{NH}_{2} \mathrm{OH}\right)$, and hydrogen peroxide $\left(\mathrm{H}_{2} \mathrm{O}_{2}\right)$ were purchased from Merck.

Samples were filtered using $0.45 \mu \mathrm{m}$ Minisart cellulose nitrate membrane filters (Sartorius, Goettingen, Germany). To check the accuracy of the analytical procedures, the certified reference materials CRM 320R Trace Elements in River Sediment, Community Bureau of Reference (Geel, Belgium), and SPS-SW1 Quality Control Material for Surface Water Analysis obtained from SPS Spectrapure Standards AS (Oslo, Norway) were used. 


\subsection{Experimental Design}

Natural, uncontaminated soil with a grain size in the range of clayey silt was dried at $40{ }^{\circ} \mathrm{C}$ and homogenized. Laboratory samples were obtained by the quartering procedure. After that, $0.5 \mathrm{~kg}$ of soil sample was treated with $10.3 \mathrm{~g}$ of gypsum $\left(\mathrm{CaSO}_{4} 2 \mathrm{H}_{2} \mathrm{O}\right)$, thus that the leachable sulfate content was equivalent to that in the contaminated soil from "Old Zinc-works" site. To individual aliquots of $0.5 \mathrm{~kg}$ of untreated and sulfate-treated natural soils, an aqueous solution of a mixture of nitrate salts $\left(\mathrm{Cd}\left(\mathrm{NO}_{3}\right)_{2}, \mathrm{~Pb}\left(\mathrm{NO}_{3}\right)_{2}\right.$, and $\left.\mathrm{Zn}\left(\mathrm{NO}_{3}\right)_{2}\right)$ was added, thus that the contaminated soils contained approximately 10 , 1000 , and $10,000 \mathrm{mg} / \mathrm{kg}$ of $\mathrm{Cd}, \mathrm{Pb}$, and $\mathrm{Zn}$, respectively. The contaminated soils were left for $48 \mathrm{~h}$ at $30^{\circ} \mathrm{C}$ to allow equilibration of the added $\mathrm{Cd}, \mathrm{Pb}$, and $\mathrm{Zn}$. Then, for the remediation, $0.25 \mathrm{~kg}$ aliquots of contaminated and sulfate-treated contaminated soils were amended with the paper-ash, thus that the soil-to-ash mass ratio was 75:25. This ratio was chosen based on the optimization of the paper ash remediation process from our previous research. After the addition of the paper-ash, water (wt. 30\%) was added [18]. Samples were homogenized, transferred to plastic cylinders (diameter: $100 \mathrm{~mm}$; height: $40 \mathrm{~mm}$ ), and compacted manually with a rammer, simulating the field installation of geotechnical composites. The composites were then transferred to a climatic chamber at $20 \pm 2{ }^{\circ} \mathrm{C}$ and $98 \%$ humidity and kept under constant temperature and humidity conditions until the end of the experiment. To follow the partitioning of the $\mathrm{Cd}, \mathrm{Pb}$, and $\mathrm{Zn}$ in the prepared uncontaminated, contaminated, and remediated soils, the modified Tessier's extraction procedure was applied in different time intervals over a time span of 365 days. Samples for the analysis were taken at 7, 28, 56, 90, 120, and 365 days after the remediation from the top and the bottom apertures of the cylinders. In uncontaminated, contaminated, and remediated soil, along with the Tessier extraction procedure, the XRD analyses were performed for each time interval. All the experiments were made using duplicate samples. A flow chart of the experimental design is presented in Figure 1.

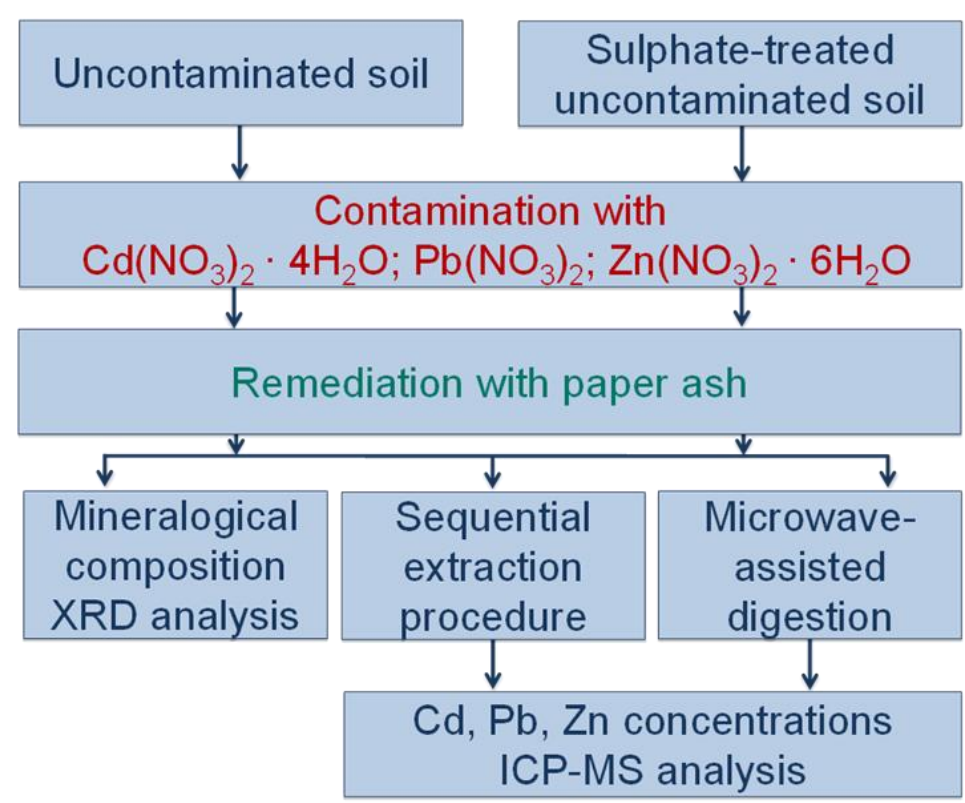

Figure 1. Flow chart of the experimental design.

\subsection{Apparatus}

Total concentrations $\mathrm{Cd}, \mathrm{Pb}$, and $\mathrm{Zn}$ in uncontaminated, contaminated, and remediated soil samples and their amounts in the individual phases of the sequential extraction procedures were determined by ICP-MS (7700x, Agilent Technologies, Tokyo, Japan). ICP-MS operating parameters are presented in Table S1 (Supplementary).

A CEM Corporation (Matthews, NC, USA) MARS 6 Microwave System was used for sample digestion. 
Mineralogical composition of soil samples was determined by X-ray powder diffraction (XRD) on the Empyrean PANalytical diffractometer (PANalytical B.V., Almelo, The Netherlands) with $\mathrm{Cu}-\mathrm{K} \alpha$ irradiation $(\lambda=1.54056 \AA)$, at $45 \mathrm{kV}$ and a current of $40 \mathrm{~mA}$, over the $2 \theta$ angular range from $5^{\circ}$ to $70^{\circ}$, using a step size of $0.01^{\circ}$ and a measuring time per step of $100 \mathrm{~s}$. The results were analyzed with the Highscore (PANalytical, Almelo, The Netherlands) diffraction software, using the Powder Diffraction File PDF-4+ (ICDD, Newtown Square, PA, USA) database as the reference source of data.

Scanning electron microscopy was performed by using a SEM 5500 LV (JEOL, Tokyo, Japan) microscope, equipped with energy dispersive spectroscopy (EDS, Oxford instruments, Abingdon, UK). During the analyses, low-vacuum mode (pressure of $20 \mathrm{~Pa}$ ) and an accelerating voltage of $15 \mathrm{kV}$ were used. A polished cross-section was prepared for SEM/EDS.

The specific surface area (BET) of paper ash was determined by nitrogen gas sorption (ASAP 2020, Micromeritics, Norcross, GA, USA). The sample was evacuated at $105^{\circ} \mathrm{C}$ with an evacuation rate of $0.67 \mathrm{kPa} / \mathrm{s}$ until a final vacuum of $2 \mathrm{~Pa}$ was attained.

During the steps of the sequential extraction procedure, samples were mechanically shaken on a Vibromix 40 elliptical (Tehtnica, Železniki, Slovenia) orbital shaker. The Hettich Universal 320 Centrifuge (Hettich GmbH \& Co. KG, Tuttlingen, Germany) was used to centrifuge the samples.

A WTW pH meter 3110 (Weilheim, Germany) pH meter was used to measure $\mathrm{pH}$. An AE 163 analytical balance from Mettler (Zürich, Switzerland) was used for weighing.

\subsection{Determination of the Total Metal Content in the Soil Samples}

For digestion of soil samples, about $0.2 \mathrm{~g}$ of dry soil was weighed into a Teflon tube, and microwave-assisted digestion was applied using $\mathrm{HNO}_{3}, \mathrm{HF}$, and $\mathrm{HCl}$ acids [36]. The concentrations of $\mathrm{Cd}, \mathrm{Pb}$, and $\mathrm{Zn}$ in the digested samples were determined by ICP-MS.

\subsection{Sequential Extraction Procedure}

To Tessier's original partitioning scheme [24], water was added as the first extracting agent to leach $\mathrm{Cd}, \mathrm{Pb}$, and $\mathrm{Zn}$ from the most mobile soil fraction [25]. A total of $2.000 \pm 0.001 \mathrm{~g}$ of soil sample were weighed in the centrifuge tube, and the sequential extraction procedure presented in Table 1 was applied. For mechanical shaking (steps I-III), an elliptical orbital shaker (300 rpm) was used. After shaking, centrifugation at 10,000 rpm (10 $\mathrm{min}$ ) and filtration of the sample through $0.45 \mu \mathrm{m}$ filter followed. Prior to the addition of the next extracting agent, the remaining solid residues were washed with $10 \mathrm{~mL}$ of water (shaken and centrifuged).

Table 1. The extraction procedure [25] used in the present study.

\begin{tabular}{|c|c|c|c|}
\hline Step & Soil Fraction & Extracting Solution & Mode of Extraction \\
\hline $\mathrm{I}$ & Water-soluble & Water $(20 \mathrm{~mL})$ & Shaking (16 h) \\
\hline II & Exchangeable & $\begin{array}{c}1 \mathrm{M} \mathrm{NaCH}_{3} \mathrm{COO}(20 \mathrm{~mL} \\
\mathrm{pH} 8.2)\end{array}$ & Shaking (1 h) \\
\hline III & Bound to carbonates & $\begin{array}{c}1 \mathrm{M} \mathrm{NaCH}_{3} \mathrm{COO}(20 \mathrm{~mL} \\
\mathrm{pH} 5)\end{array}$ & Shaking (5 h) \\
\hline IV & $\begin{array}{c}\text { Bound to } \mathrm{Fe} / \mathrm{Mn} \text { oxides } \\
\text { and hydroxides }\end{array}$ & $\begin{array}{c}0.04 \mathrm{M} \mathrm{NH}_{2} \mathrm{OH} \mathrm{HCl} \text { in } \\
25 \% v / v \mathrm{CH}_{3} \mathrm{COOH} \\
(20 \mathrm{~mL}, \mathrm{pH} 2)\end{array}$ & Extracted at $95^{\circ} \mathrm{C}(6 \mathrm{~h})$ \\
\hline $\mathrm{V}$ & Bound to organic matter & $\begin{array}{c}156.25 \mathrm{~mL} \text { of } 30 \% \mathrm{H}_{2} \mathrm{O}_{2}+ \\
93.75 \mathrm{~mL} \text { of } 0.02 \mathrm{M} \\
\mathrm{HNO}_{3}(20 \mathrm{~mL}, \mathrm{pH} 2)\end{array}$ & Extracted at $85^{\circ} \mathrm{C}(2 \mathrm{~h})$ \\
\hline VI & Bound to silicate lattice & $\begin{array}{l}0.2 \mathrm{~g} \text { of dried } \\
\text { residual sample }\end{array}$ & $\begin{array}{c}\text { Microwave-assisted } \\
\text { digestion }\end{array}$ \\
\hline
\end{tabular}




\section{Results and Discussion \\ 3.1. Quality Control of the Analytical Data}

The accuracy of the analytical procedures for the determination of the $\mathrm{Cd}, \mathrm{Pb}$, and $\mathrm{Zn}$ concentrations in extracts from the sequential extraction procedure and the total element concentrations in the soil samples was checked by analyzing the SPS-SW1 Reference material for the measurements of elements in surface waters and certified reference materials CRM 320R Trace elements in river sediment. As evident from data given in Tables S2 and S3, the determined concentrations of the elements agreed well with the reported certified values (the agreement between the results was better than $\pm 5 \%$ ), which confirmed the accuracy of the analytical procedures. The expanded uncertainty of the analytical procedures applied was better than $\pm 3 \%(k=2)$.

\subsection{Characteristics of the Soil and Paper-Ash}

The mineralogical composition of the soil used is presented in the Supplementary Material (Figure S1). The results of the XRD analyses revealed that the soil is composed of quartz, dolomite, feldspar, calcite, illite/muscovite, clinochlore, and hornblende. The paper-ash is a fine-grade, highly alkaline $(\mathrm{pH} 12)$ hydraulically active material, with a specific surface area (BET) of $8.1 \mathrm{~m}^{2} / \mathrm{g}$, containing approximately $40 \% \mathrm{Ca}, 6 \% \mathrm{Si}, 5 \% \mathrm{Al}$, and $2 \% \mathrm{Mg}$. $\mathrm{Ba}, \mathrm{Fe}, \mathrm{S}, \mathrm{K}, \mathrm{Zn}$, and $\mathrm{Ni}$ are present in lower concentrations and some other elements in trace amounts. Phase analyses revealed the presence of calcite, lime, portlandite, quartz, talc, gehlenite, anhydrite, and dolomite, together with an amorphous phase. SEM/EDS analysis results correlated with the XRD analysis (Figure 2A). The amorphous phase consists primarily of $\mathrm{Si}, \mathrm{Al}$, and $\mathrm{Ca}$ in different proportions (Figure $2 \mathrm{~B}$ ). Based on the leaching test, applying the standardized leaching procedure [37,38], it was found that the above-mentioned elements are present in paper-ash as low water-soluble species. Only the concentration of $\mathrm{Ba}$ exceeded the limiting value for inert materials, set by the current Slovenian landfilling legislation [37,38].

(A)

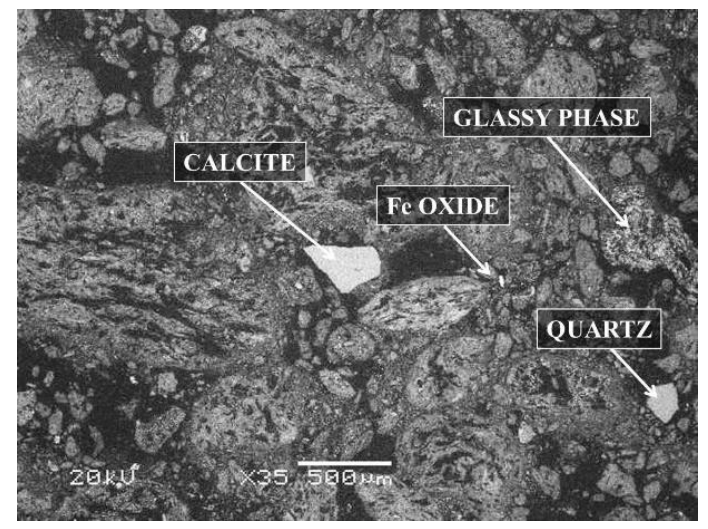

(B)

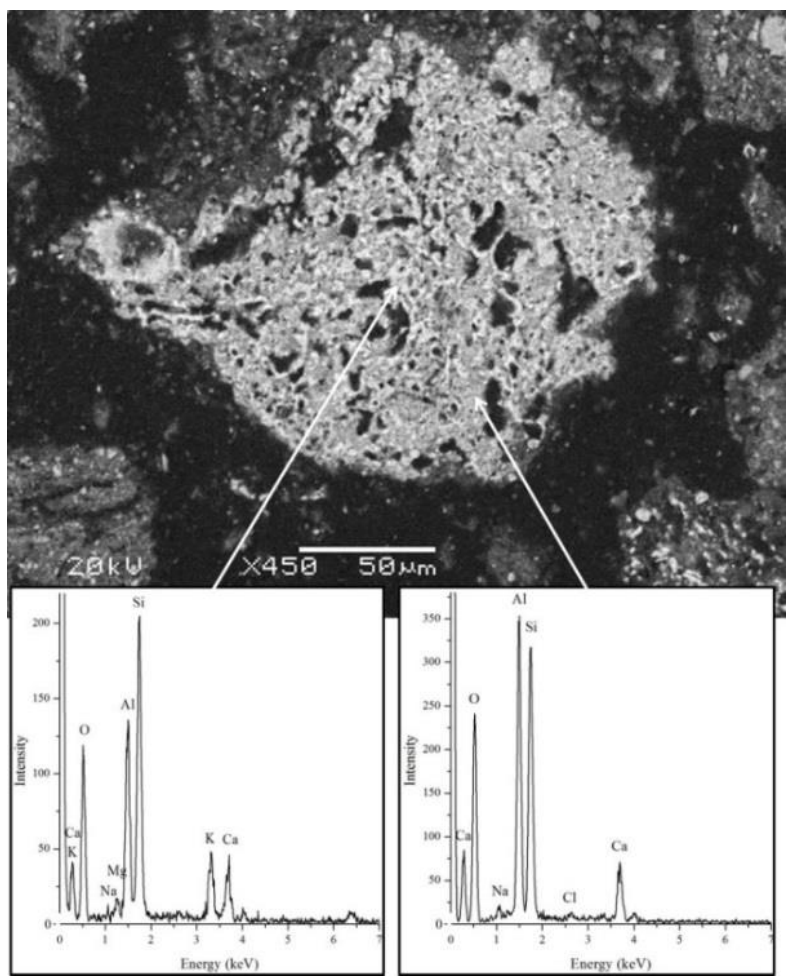

Figure 2. SEM micrographs of the paper ash; (A) showing the presence of different constituent phases; (B) the results of the semi-quantitative chemical analysis (EDS) of paper ash amorphous phase. 
To separately follow the carbonation process for the paper-ash itself, a paste was prepared by mixing the paper-ash with an excess amount of demineralized water. The XRD analyses were performed at seven different time intervals to define the evolution of the calcite and portlandite mineral phases. The results in Figure S2 showed an increase in the relative quantity of calcite and a decrease in the relative quantity of portlandite.

3.3. Investigation of the Immobilization Mechanisms, Stability of the Mineral Phases of $\mathrm{Cd}, \mathrm{Pb}$, and $\mathrm{Zn}$ after the Remediation, and the Environmental Impacts of Soil Remediation

To study the mechanisms of immobilization and the stability of the mineral phases of $\mathrm{Cd}, \mathrm{Pb}$, and $\mathrm{Zn}$ after remediation, and to evaluate the environmental impacts of soil remediation, partitioning of $\mathrm{Cd}, \mathrm{Pb}$, and $\mathrm{Zn}$ were performed in uncontaminated, contaminated, and remediated soils over a period of one year in different time intervals by applying a sequential extraction procedure and the data were compared with complementary results from the XRD analyses.

\subsection{Partitioning of $\mathrm{Cd}, \mathrm{Pb}$, and $\mathrm{Zn}$ in Uncontaminated, Contaminated, and Remediated Soils}

Partitioning of $\mathrm{Cd}, \mathrm{Pb}$, and $\mathrm{Zn}$ was performed in uncontaminated, contaminated, and remediated soils by applying a modified Tessier's sequential extraction procedure [24] (see sequential extraction procedure in Materials and methods). To find out whether sulfate, as present in the soil from "Old Zinc-works" site, has any effect on the remediation, sulfate-treated uncontaminated, contaminated, and remediated soils were also investigated (see Experimental design). The results of the partitioning of the $\mathrm{Cd}, \mathrm{Pb}$, and $\mathrm{Zn}$ in the uncontaminated, contaminated, and remediated soils are presented in Figures 3-5, while in sulfate-treated uncontaminated, contaminated, and remediated soils in the Supplementary Material (Figures S3-S5). The related elemental concentrations in individual soil fractions of the extraction procedure related to data from Figures 3-5 and Figures S3-S5 are provided in the Supplementary Material (Tables S4-S9). The concentrations of $\mathrm{Cd}, \mathrm{Pb}$, and $\mathrm{Zn}$ in steps I to VI were summed and compared to the total $\mathrm{Cd}, \mathrm{Pb}$, and $\mathrm{Zn}$ concentrations obtained by microwave-assisted digestion. The mass balance was agreed to within $\pm 5 \%$, confirming the precision of the sequential extraction analysis.
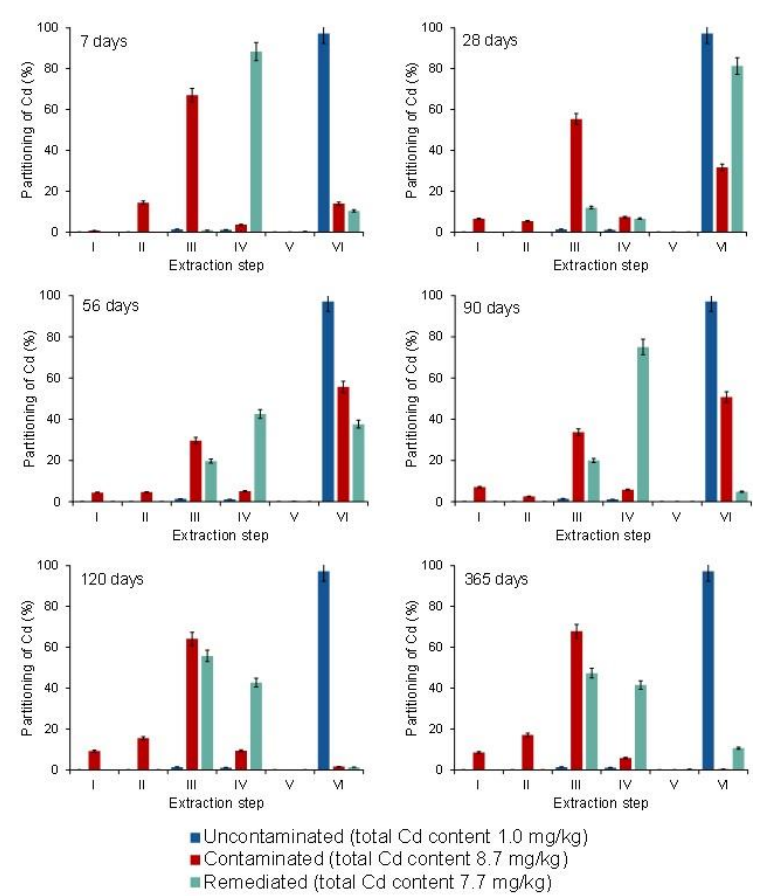

Figure 3. Partitioning of $\mathrm{Cd}$ in uncontaminated, contaminated, and remediated soil samples with time elapsed after the remediation. I water-soluble; II exchangeable; III bound to carbonates; IV bound to $\mathrm{Fe} / \mathrm{Mn}$ oxides and hydroxides; V bound to organic matter; VI bound to silicate lattice. 

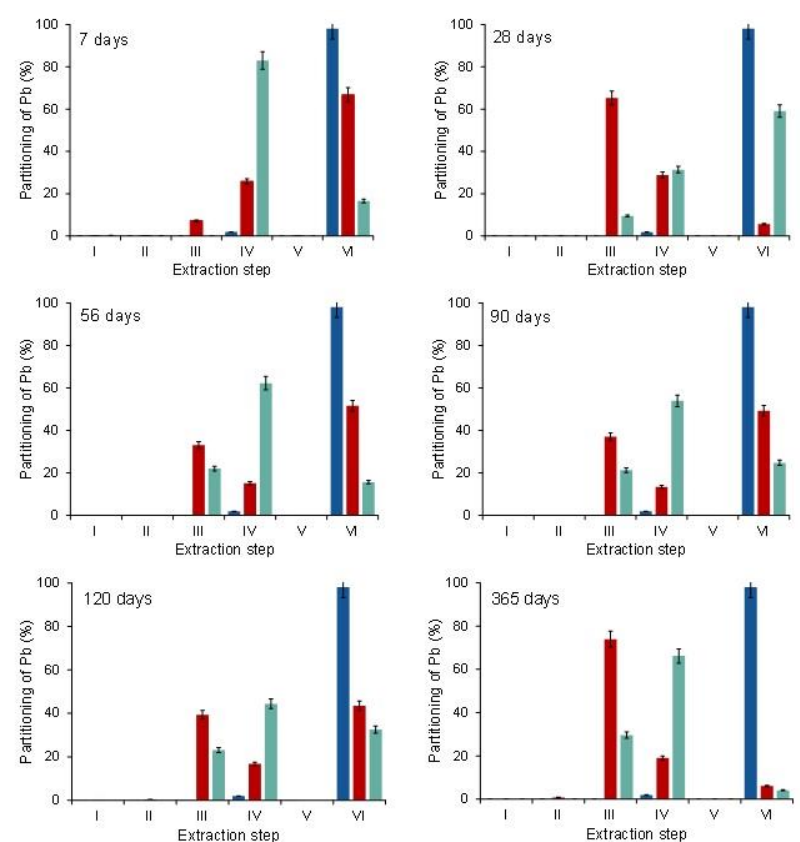

$$
\begin{aligned}
& \text { - Uncontaminated (total Pb content } 9.5 \mathrm{mg} / \mathrm{kg} \text { ) } \\
& \text { - Contaminated (total Pb content } 946 \mathrm{mg} / \mathrm{kg} \text { ) } \\
& \text { - Remediated (total Pb content } 767 \mathrm{mg} / \mathrm{kg} \text { ) }
\end{aligned}
$$

Figure 4. Partitioning of $\mathrm{Pb}$ in uncontaminated, contaminated, and remediated soil samples with time elapsed after the remediation. I water-soluble; II exchangeable; III bound to carbonates; IV bound to $\mathrm{Fe} / \mathrm{Mn}$ oxides and hydroxides; V bound to organic matter; VI bound to silicate lattice.
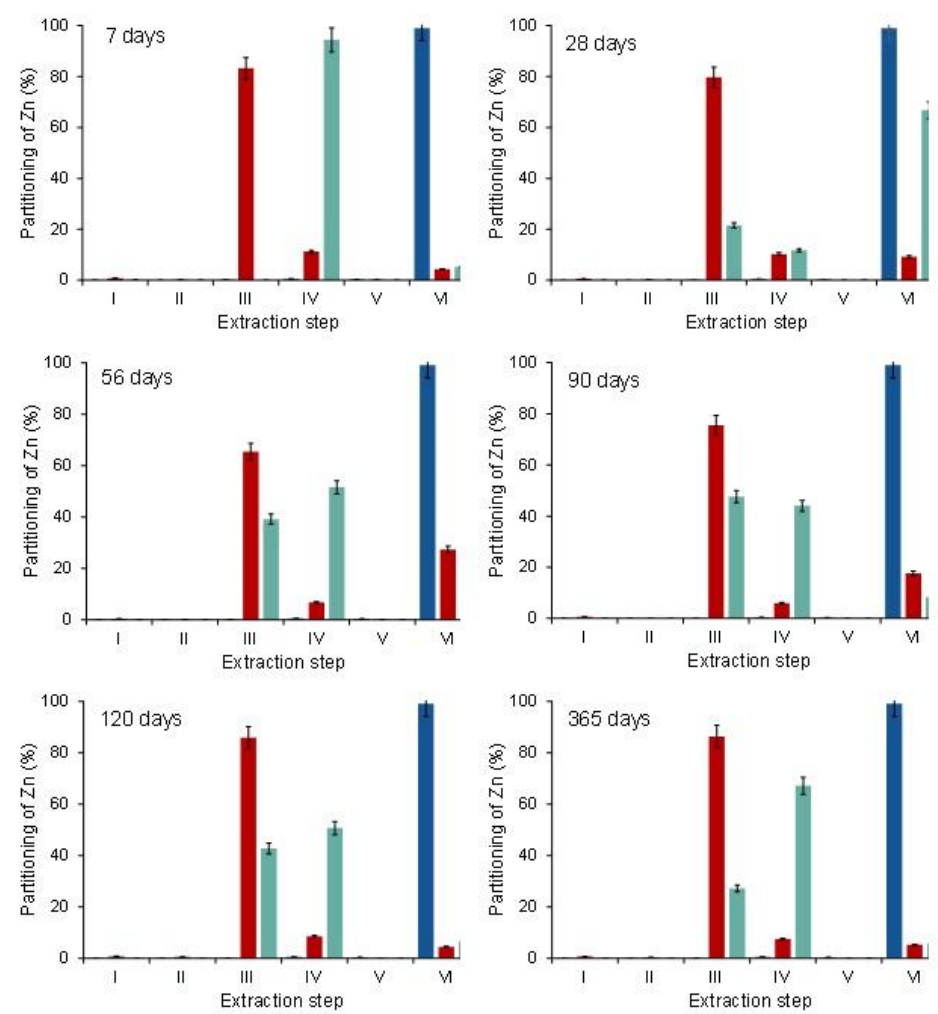

- Uncontaminated (total Zn content $41.3 \mathrm{mg} / \mathrm{kg}$ )

- Contaminated (total Zn content $8814 \mathrm{mg} / \mathrm{kg}$ )

$=$ Remediated (total Zn content $7491 \mathrm{mg} / \mathrm{kg}$ )

Figure 5. Partitioning of $\mathrm{Zn}$ in uncontaminated, contaminated, and remediated soil samples with time elapsed after the remediation. I water-soluble; II exchangeable; III bound to carbonates; IV bound to $\mathrm{Fe} / \mathrm{Mn}$ oxides and hydroxides; V bound to organic matter; VI bound to silicate lattice. 
In the uncontaminated soils, $\mathrm{Cd}, \mathrm{Pb}$, and $\mathrm{Zn}$ were associated almost exclusively with the insoluble residual fraction, bound to the silicate lattice. Their concentrations in the water-soluble and exchangeable fractions, which are mobile in the environment, were negligible, not exceeding $0.0007,0.0003$, and $0.0025 \mathrm{mg} / \mathrm{kg}$ for the $\mathrm{Cd}, \mathrm{Pb}$, and $\mathrm{Zn}$, respectively (see the data from Tables S4-S9).

In the contaminated soils, the distribution of $\mathrm{Cd}, \mathrm{Pb}$, and $\mathrm{Zn}$ changed over time. After the contamination, the $\mathrm{Cd}$ was distributed mainly between the carbonate, exchangeable and residual fractions. In the water-soluble fraction, the $\mathrm{Cd}$ concentration exceeded the limiting value for inertness $(0.04 \mathrm{mg} / \mathrm{kg})[37,38]$. During the experiment, the sum of the $\mathrm{Cd}$ concentrations in highly the mobile water-soluble and exchangeable fractions was around $2-3 \mathrm{mg} / \mathrm{kg}$. The $\mathrm{Pb}$ in the contaminated soils was associated with carbonate, $\mathrm{Fe} / \mathrm{Mn}$ oxides and hydroxides, and the residual fractions. After the soil contamination, the $\mathrm{Pb}$ concentration in the water-soluble fraction was close to the limit value for inert materials $(0.5 \mathrm{mg} / \mathrm{kg})[37,38]$, while its exchangeable concentrations were up to 30 times higher than in the water-soluble fraction (see data from Tables S4-S9). The Zn in the contaminated soils was distributed mainly in the carbonate fraction and, to a smaller extent, in the $\mathrm{Fe} / \mathrm{Mn}$ oxides and hydroxides and residual fractions. In the water-soluble fraction of the contaminated soils, the $\mathrm{Zn}$ concentrations greatly exceeded (around 20 times) the criterion for inertness $(4 \mathrm{mg} / \mathrm{kg})[37,38]$, whereas the exchangeable $\mathrm{Zn}$ contents were approximately 2-4 times lower than the water-soluble concentrations.

In the remediated soils, the application of paper-ash substantially increased the soil's $\mathrm{pH}$, which led to the precipitation of $\mathrm{Cd}, \mathrm{Pb}$, and $\mathrm{Zn}$ and their transfer from the easily soluble fractions to the sparingly soluble fraction associated with $\mathrm{Fe} / \mathrm{Mn}$ oxides and hydroxides. In the early stage of remediation (Figures 3-5, soils that were not treated with sulfate), the $\mathrm{Cd}, \mathrm{Pb}$, and $\mathrm{Zn}$ were associated mainly with $\mathrm{Fe} / \mathrm{Mn}$ oxides and hydroxides. After 28 days, $\mathrm{Cd}$ and $\mathrm{Zn}$ were redistributed to the residual fraction, while the $\mathrm{Pb}$ was between the residual and the fraction bound to $\mathrm{Fe} / \mathrm{Mn}$ oxides and hydroxides. As the time elapsed, the $\mathrm{CaO}$ present in the paper-ash was hydrated, forming $\mathrm{Ca}(\mathrm{OH})_{2}$ that, through the carbonation process, yielded $\mathrm{CaCO}_{3}$. The newly formed carbonates, along with the hydroxides, bound the $\mathrm{Cd}, \mathrm{Pb}$, and $\mathrm{Zn}$ into insoluble compounds. The solubilities of the $\mathrm{Cd}, \mathrm{Pb}$, and $\mathrm{Zn}$ carbonates and hydroxides are presented in Table 2 (data from IUPAC-NIST Solubility Database [39].

Table 2. Solubility of $\mathrm{CdCO}_{3}, \mathrm{PbCO}_{3}$, and $\mathrm{ZnCO}_{3}$, and $\mathrm{Cd}(\mathrm{OH})_{2}, \mathrm{~Pb}(\mathrm{OH})_{2}$, and $\mathrm{Zn}(\mathrm{OH})_{2}$ in water at $20{ }^{\circ} \mathrm{C}$ based on IUPAC Solubility Database (2012).

\begin{tabular}{cc}
\hline Compound & Solubility (g/100 $\mathbf{~ m L})$ \\
\hline $\mathrm{CdCO}_{3}$ & $3.932 \times 10^{-5}$ \\
$\mathrm{Cd}(\mathrm{OH})_{2}$ & $2.697 \times 10^{-4}$ \\
$\mathrm{PbCO}_{3}$ & $7.269 \times 10^{-5}$ \\
$\mathrm{~Pb}(\mathrm{OH})_{2}$ & $1.615 \times 10^{-4}$ \\
$\mathrm{ZnCO}$ & $4.692 \times 10^{-5}$ \\
$* \mathrm{Zn}(\mathrm{OH})_{2}$ & $1 \times 10^{-4}$ \\
\hline
\end{tabular}

* Because of divergent results reported, provided value is approximate estimation, (IUPAC Solubility Database [39]).

After the stabilization in the mineral phases, until the end of the experiment, the $\mathrm{Cd}$, $\mathrm{Pb}$, and $\mathrm{Zn}$ remained associated mainly with the carbonate fraction and the fraction bound to the $\mathrm{Fe} / \mathrm{Mn}$ oxides and hydroxides.

The data from Figures 3-5 and Figures S3-S5 further indicate that the addition of sulfate to soil samples had no effect on the remediation efficiency. The partitioning of $\mathrm{Cd}$, $\mathrm{Pb}$, and $\mathrm{Zn}$ in the remediated soil, which was not treated with sulfate (Figures 3-5), and in the sulfate-treated remediated soil (Figures S3-S5), was almost the same.

Due to the redistribution of $\mathrm{Cd}, \mathrm{Pb}$, and $\mathrm{Zn}$ from the water-soluble and the exchangeable fractions into the sparingly soluble fractions of soil composite (the formation of insoluble $\mathrm{Cd}, \mathrm{Pb}$, and $\mathrm{Zn}$ carbonates and hydroxides), the $\mathrm{Cd}, \mathrm{Pb}$, and $\mathrm{Zn}$ concentrations in 
the easily soluble fractions significantly decreased, indicating the effective remediation of the contaminated soil by paper-ash.

The $\mathrm{Cd}$ concentration in the water-soluble fraction after the remediation was reduced from 0.8 to approximately $0.0005 \mathrm{mg} / \mathrm{kg}$ (Tables S4 and S7), which is 100 times lower than the limiting value for inert materials $[37,38]$. In the exchangeable fraction, this decrease was from 1.5 to $0.0005 \mathrm{mg} / \mathrm{kg}$ (3000 times), demonstrating the effective immobilization of $\mathrm{Cd}$ also from the exchangeable fraction. The $\mathrm{Pb}$ concentration, which during the course of the experiment in the water-soluble fraction of contaminated soils, in general, ranged from 0.2 to $0.8 \mathrm{mg} / \mathrm{kg}$, was reduced by about 250 times after the remediation (Tables S5 and S8). The concentrations of $\mathrm{Pb}$ in the water-soluble fraction were about 125 times lower than the limit value for inert materials $[37,38]$. In the exchangeable fraction of soil that was not treated with sulfate, this decrease was from 8 to $0.1 \mathrm{mg} / \mathrm{kg}$ ( 80 times) after the remediation (Table S5), indicating the effective immobilization of $\mathrm{Pb}$ also in this easily soluble soil fraction. The effective immobilization of $\mathrm{Pb}$ from the exchangeable fraction was also observed in the sulfate-treated and remediated soil (Table S8). The Zn concentration in the water-soluble fraction was reduced from about 60 to $0.4 \mathrm{mg} / \mathrm{kg}$ (Table S6) after the remediation, which is 10 times lower than the limiting value for inert materials [37,38]. In the case of $\mathrm{Zn}$, similar concentrations were found in the sulfate-treated remediated soils (Table S9). In the exchangeable fraction, the $\mathrm{Zn}$ concentrations in soil that were not treated with sulfate decreased after the remediation by about 50 times, and in the sulfate-treated soil by about 100 times (Tables S6 and S9). This shows that the immobilization of $\mathrm{Zn}$ was also effective in the exchangeable soil fraction.

It is important to stress that the $\mathrm{Cd}, \mathrm{Pb}$, and $\mathrm{Zn}$ were already effectively immobilized 28 days after the remediation and remained stabilized in the sparingly soluble soil composite fractions until the end of the experiment (1 year), demonstrating the remediation efficiency as well as the stability of the formed $\mathrm{Cd}, \mathrm{Pb}$, and $\mathrm{Zn}$ compounds. Since after the remediation the concentrations of $\mathrm{Cd}, \mathrm{Pb}$, and $\mathrm{Zn}$ in the water-soluble fraction were far below the limiting values for inertness $[37,38]$ and thus were their concentrations in the exchangeable fraction, the $\mathrm{Cd}, \mathrm{Pb}$, and $\mathrm{Zn}$ in the remediated soil composites do not present an environmental hazard.

In an evaluation of the possible statistical significance of differences between the distribution of $\mathrm{Cd}, \mathrm{Pb}$, and $\mathrm{Zn}$ in contaminated and remediated soils, mean values $(n=6)$ from distribution of $\mathrm{Cd}, \mathrm{Pb}$, and $\mathrm{Zn}$ between the fractions of the Tessier's sequential extraction were compared by computing Student's t-test. In the water-soluble, exchangeable, bound to carbonates, and fraction bound to $\mathrm{Fe} / \mathrm{Mn}$ oxides and hydroxides, there were statistically significant differences between the means of $\mathrm{Cd}, \mathrm{Pb}$, and $\mathrm{Zn}$ concentrations, when a probability of $\leq 0.05$ was considered as significant. In the fraction bound to organic matter and sulfide, no statistically significant differences between the means of $\mathrm{Cd}, \mathrm{Pb}$, and Zn concentrations were observed when a probability of $\leq 0.05$ was considered as significant (Table S10). This was expected since, in this fraction, very low elements concentrations were found in contaminated and remediated soils. In the residual fraction, it was not possible to apply Student's $t$-test due to large differences in $\mathrm{Cd}, \mathrm{Pb}$, and $\mathrm{Zn}$ concentrations determined at different time intervals in this fraction.

\subsection{Investigation of the Mineralogical Composition of the Remediated Soils}

To identify the mineral phases that were formed after the remediation, XRD analyses were performed in uncontaminated, contaminated, and remediated soils during each time interval as a sequential extraction procedure. In the case of contaminated soil without the addition of gypsum, there is no difference in XRD spectra in comparison to the uncontaminated soil, neither from the scope of analysis of crystalline phases nor from the scope of analyses for the potential presence of amorphous phases. In addition, there was no difference between the contaminated soil with the addition of gypsum in comparison to the uncontaminated soil with the addition of gypsum. The only difference between the 
contaminated soil and contaminated soil with added gypsum was that the characteristic peaks of gypsum were detected in the XRD spectra of the latter, as can be seen in Figure S6.

The potential formation of secondary crystalline and amorphous phases of $\mathrm{Cd}, \mathrm{Pb}$, and $\mathrm{Zn}$ minerals was somehow expected after artificial contamination of soil. Therefore, special care was taken during the refinement of the XRD spectra to identify the potential presence of commonly occurring $\mathrm{Cd}, \mathrm{Pb}$, and $\mathrm{Zn}$ carbonate and sulfate minerals. However, no such phases were identified.

Since the data from the partitioning study revealed that the sulfate treatment does not influence the remediation efficiency, only the soils that were not treated with sulfate are presented. Sections of the XRD patterns of the contaminated and remediated soils, along with the XRD patterns of the uncontaminated soil, are presented in Figure 6.

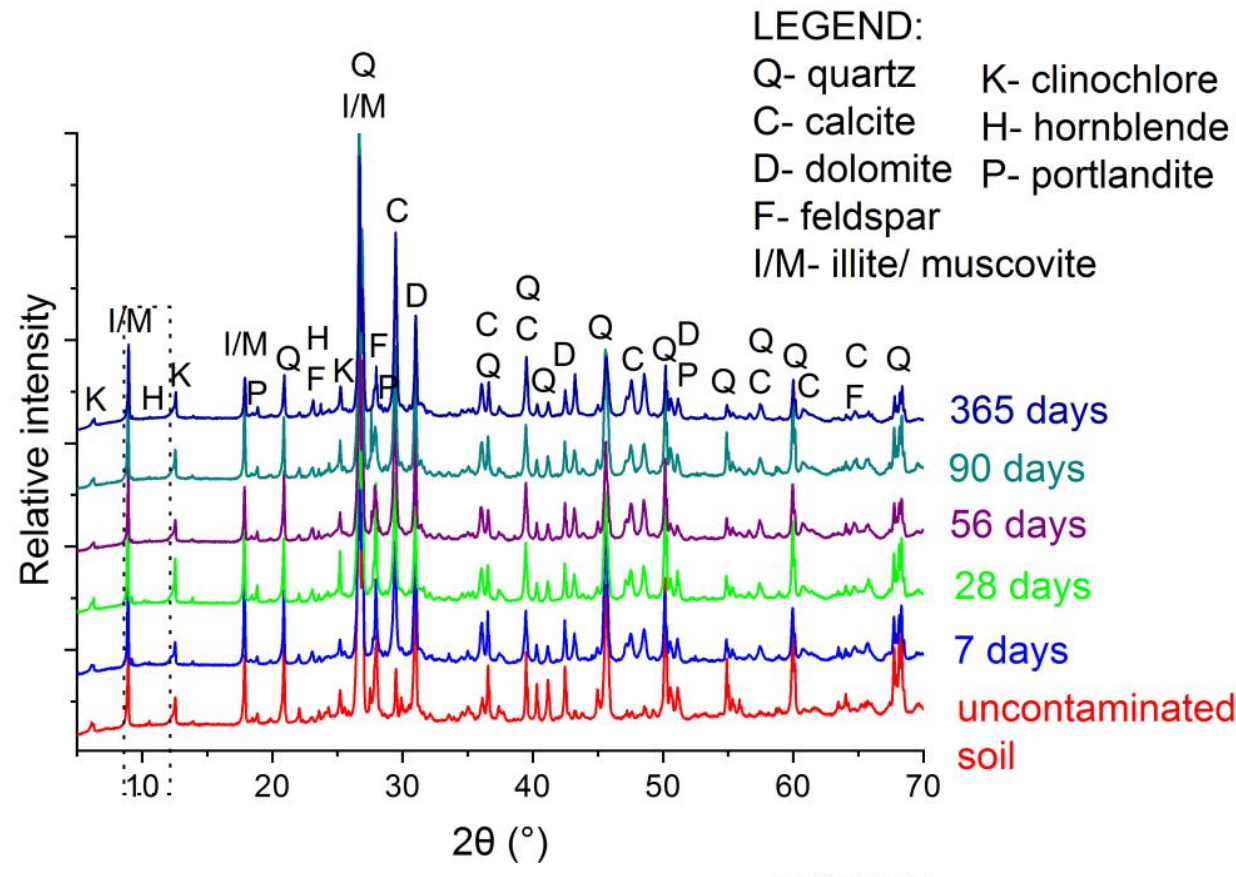

LEGEND:

Ms- monosulphoaluminate

A

Q- quartz K- clinochlore

C- calcite H- hornblende

D- dolomite P-portlandite

F- feldspar

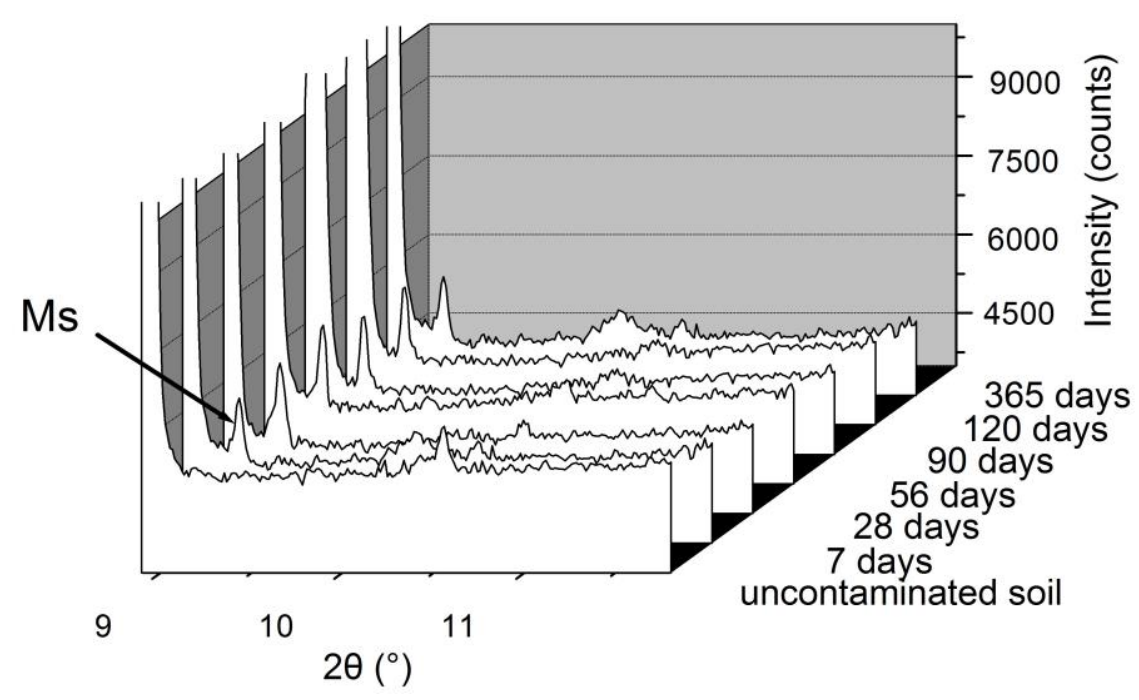

Figure 6. XRD patterns of $(\mathbf{A})$ remediated soil and (B) corresponding section of the XRD patterns from $8.9^{\circ}-11.8^{\circ} 2 \theta$ with time elapsed after the remediation. 
The results of the XRD analyses showed that a new mineral phase was formed due to the addition of paper-ash to the soil. A mono-sulpho-aluminate hydration product from the group of calcium aluminate hydrate minerals $(\mathrm{CAH})$ was identified. Its relative quantity was not changed significantly during the experiment. The hydration product $\mathrm{CAH}$, which was formed in the remediated soils, and the carbonation process, which was proven in the case of paper-ash, contribute to the effective immobilization of the $\mathrm{Cd}, \mathrm{Pb}$, and $\mathrm{Zn}$. These XRD data supported the results obtained by the sequential extraction procedure.

In the reported literature, the BCR extraction scheme [30], the Tessier's sequential extraction procedure [31], and the use of sequential extraction procedures in combination with XRD analysis [34,35] were reported for the investigation of the immobilization of heavy metals in the soil after the remediation with different soil amendments. Since in these articles sequential extraction procedures were applied for only one-time interval after the remediation, by the reported approaches [30,31,34,35], it was only possible to estimate the efficiency of remediation by evaluating the redistribution of metals from the easily soluble to more sparingly soluble soil mineral phases. In the present investigation, the use of modified Tessier's sequential extraction procedure in combination with the complementary XRD analysis performed in time intervals of 7, 28, 56, 90, 120, and 365 days after the remediation, enabled us to follow the mechanisms of the remediation of $\mathrm{Cd}, \mathrm{Pb}$, and $\mathrm{Zn}$ with paper-ash, the study of the efficiency of the remediation and the stability of the newly formed insoluble mineral phases of $\mathrm{Cd}, \mathrm{Pb}$, and $\mathrm{Zn}$. To the best of our knowledge, such a comprehensive methodological approach has not yet been reported.

\section{Conclusions}

Data from the present investigation based on a sequential extraction procedure and $\mathrm{XRD}$ analyses revealed that paper-ash is an effective additive for the immobilization process in remediation of $\mathrm{Cd}, \mathrm{Pb}$, and $\mathrm{Zn}$ in contaminated soils. Sulfate added to the soil did not affect the remediation efficiency. In the remediated soil composites, the $\mathrm{Cd}, \mathrm{Pb}$, and $\mathrm{Zn}$ were transferred from the easily soluble, highly mobile soil fractions to the sparingly soluble fractions of soil composite. Consequently, their concentrations in the water-soluble fraction were reduced far below the limit values for inert materials $(\mathrm{Cd}$ concentration was reduced from 0.8 to $0.0005 \mathrm{mg} / \mathrm{kg}$, Pb concentration from 0.8 to $0.003 \mathrm{mg} / \mathrm{kg}$, and $\mathrm{Zn}$ concentration from 60 to $0.4 \mathrm{mg} / \mathrm{kg}$ ). A significant decrease in the $\mathrm{Cd}, \mathrm{Pb}$, and $\mathrm{Zn}$ concentrations was also observed in the exchangeable fraction of the soil composite $(\mathrm{Cd}$ concentration was reduced from 1.5 to $0.0005 \mathrm{mg} / \mathrm{kg}, \mathrm{Pb}$ concentration from 8 to $0.1 \mathrm{mg} / \mathrm{kg}$, and $\mathrm{Zn}$ concentration from 40 to $0.5 \mathrm{mg} / \mathrm{kg}$ ).

The mechanism of immobilization for the $\mathrm{Cd}, \mathrm{Pb}$, and $\mathrm{Zn}$ with paper-ash involved the formation of hydration products from the paper-ash, which resulted in the precipitation of insoluble $\mathrm{Cd}, \mathrm{Pb}$, and $\mathrm{Zn}$ hydroxides, while through the carbonation process, $\mathrm{Cd}, \mathrm{Pb}$, and Zn were stabilized in insoluble carbonates.

The present study revealed the high efficiency of the remediation with paper-ash, which is related to the stability of the hydroxide and carbonate mineral phases of $\mathrm{Cd}$, $\mathrm{Pb}$, and $\mathrm{Zn}$, formed after the remediation. Regarding the environmental impacts of soil remediation with paper-ash, it was demonstrated that the $\mathrm{Cd}, \mathrm{Pb}$, and $\mathrm{Zn}$ in the remediated soil composites do not present an environmental hazard.

To the best of our knowledge, such a comprehensive investigation using complementary analytical methodologies allowed us to understand the mechanisms of $\mathrm{Cd}, \mathrm{Pb}$, and $\mathrm{Zn}$ immobilization in geotechnical composites made from contaminated soil and paper-ash and their environmental impacts has not yet been performed.

The results of this study provide novel findings and contribute important knowledge to strategies for effective remediation of soils contaminated with $\mathrm{Cd}, \mathrm{Pb}$, and $\mathrm{Zn}$ by means of immobilization with paper-ash. The new findings can contribute to more sustainable management and use of waste materials generated in the paper and pulp industry for the remediation and rehabilitation of degraded areas. New knowledge can also initiate an industrial symbiosis of a closed-loop system that can be established locally. 
From the scope of demands to achieve long-term efficiency of the soil remediation procedures with the immobilization approach, in addition to the laboratory experiments, there is a need for performing similar field tests, which will be a topic of our next investigations.

Supplementary Materials: The following are available online at https: / www.mdpi.com/article/ 10.3390/app112411822/s1, Table S1: ICP-MS operating parameters for determination of element concentrations, Table S2: Concentrations of elements in standard reference material SPS-SW1 (Reference material for measurements of elements in surface waters) determined by ICP-MS, Table S3: Concentrations of elements in certified reference material CRM 320R (Trace Elements in River Sediment) determined by ICP-MS after microwave assisted digestion, Table S4: Concentrations of Cd in individual fractions of extraction procedure in uncontaminated, contaminated, and remediated soils during the course of the experiment, Table S5: Concentrations of $\mathrm{Pb}$ in individual fractions of extraction procedure in uncontaminated, contaminated, and remediated soils during the course of the experiment, Table S6: Concentrations of $\mathrm{Zn}$ in individual fractions of extraction procedure in in uncontaminated, contaminated, and remediated soils during the course of the experiment, Table S7: Concentrations of $\mathrm{Cd}$ in individual fractions of extraction procedure in uncontaminated soil treated with $\mathrm{CaSO}_{4}$, contaminated and remediated soils during the course of the experiment, Table S8: Concentrations of $\mathrm{Pb}$ in individual fractions of extraction procedure in uncontaminated soil treated with $\mathrm{CaSO}_{4}$, contaminated and remediated soils during the course of the experiment, Table S9: Concentrations of $\mathrm{Zn}$ in individual fractions of extraction procedure in uncontaminated soil treated with $\mathrm{CaSO}_{4}$, contaminated and remediated soils during the course of the experiment, Table S10: Data on the statistical processing of the results, Figure S1: XRD pattern of uncontaminated soil, Figure S2: Sections of the XRD patterns of the paper ash paste, Figure S3: Partitioning of Cd in sulphate-treated uncontaminated, contaminated, and remediated soil samples with time elapsed after the remediation, Figure S4: Partitioning of $\mathrm{Pb}$ in sulphate-treated uncontaminated, contaminated, and remediated soil samples with time elapsed after the remediation, Figure S5: Partitioning of $\mathrm{Zn}$ in sulphate-treated uncontaminated, contaminated, and remediated soil samples with time elapsed after the remediation, Figure S6: XRD patterns of contaminated soil (A) and sulphate-treated contaminated soil (B) with time elapsed.

Author Contributions: Planning and performance of experiments, ICP-MS measurements, writing of the draft manuscript, M.Đ.; design of experiments, review, and editing, supervision, A.M.; design of experiments, P.O.; performance of XRD analysis, writing of the draft manuscript, V.Z.S.; review, A.M.P.; design of experiments, review, and editing, supervision, J.Š.; design of experiments, review and editing, R.M. All authors have read and agreed to the published version of the manuscript.

Funding: This research and the APC were funded by the Slovenian Research Agency (ARRS) for program groups P1-0143 and P2-0273 and Junior Researcher Grants for Marija Đurić (52082).

Institutional Review Board Statement: Not applicable.

Informed Consent Statement: Not applicable.

Data Availability Statement: All the data related to the paper are provided in the main manuscript and the supplementary materials. Additional data related to this paper may be available from the corresponding author on request.

Conflicts of Interest: The authors declare no conflict interests.

\section{References}

1. Gong, Y.; Zhao, D.; Wang, Q. An overview of field-scale studies on remediation of soil contaminated with heavy metals and metalloids: Technical progress over the last decade. Water Res. 2018, 147, 440-460. [CrossRef] [PubMed]

2. Li, C.; Zhou, K.; Qin, W.; Tian, C.; Qi, M.; Yan, X.; Han, W. A review on heavy metals contamination in soil: Effects, sources, and remediation techniques. Soil Sediment Contam. J. 2019, 28, 380-394. [CrossRef]

3. Rodríguez-Eugenio, N.; McLaughlin, M.; Pennock, D. Soil Pollution: A Hidden Reality; FAO: Rome, Italy, 2018; Volume 142, ISBN 978-92-5-130505-8.

4. Violante, A.; Cozzolino, V.; Perelomov, L.; Caporale, A.G.; Pigna, M. Mobility and bioavailability of heavy metals and metalloids in the soil environments. J. Soil Sci. Plant Nutr. 2010, 10, 268-292. [CrossRef]

5. Zwolak, A.; Sarzyńska, M.; Szpyrka, E.; Stawarczyk, K. Sources of soil pollution by heavy metals and their accumulation in vegetables: A review. Water Air Soil Pollut. 2019, 230, 164. [CrossRef] 
6. Pérez, A.P.; Eugenio, N.R. Status of Local Soil Contamination in Europe: Revision of the Indicator Progress in the Management Contaminated Sites in Europe; EUR 29124 EN; Publications Office of the European Union: Luxembourg, 2018; p. JRC107508. ISBN 978-92-79-80072-6. [CrossRef]

7. Bolan, N.; Kunhikrishnan, A.; Thangarajan, R.; Kumpiene, J.; Park, J.; Makino, T.; Kirkham, M.B.; Scheckel, K. Remediation of heavy metal(loid)s contaminated soils-To mobilize or to immobilize? J. Hazard. Mater. 2014, 266, 141-166. [CrossRef]

8. Khalid, S.; Shahid, M.; Niazi, N.K.; Murtaza, B.; Bibi, I.; Dumat, C. A comparison of technologies for remediation of heavy metal contaminated soils. J. Geochem. Explor. B 2017, 182, 247-268. [CrossRef]

9. Nejad, Z.D.; Jung, M.C.; Kim, K. Remediation of soils contaminated with heavy metals with an emphasis on immobilization technology. Environ. Geochem. Health 2018, 40, 27-953. [CrossRef]

10. Pandey, A.; Rabbani, A. Soil stabilisation using cement. Int. J. Civ. Eng. Technol. 2017, 8, 316-322.

11. Yi, X.; Xuefeng, L.; Yingming, X.; Xu, Q.; Qingqing, H.; Lin, W.; Yuebing, S. Remediation of heavy metal-polluted agricultural soils using clay minerals: A review. Pedosphere 2017, 27, 193-204. [CrossRef]

12. Radziemska, M.; Wyszkowski, M.; Bęś, A.; Mazur, Z.; Jeznach, J.; Brtnický, M. The applicability of compost, zeolite and calcium oxide in assisted remediation of acidic soil contaminated with $\mathrm{Cr}(\mathrm{III})$ and $\mathrm{Cr}(\mathrm{VI})$. Environ. Sci. Pollut. Res. 2019, 26, 21351-21362. [CrossRef] [PubMed]

13. Wang, M.; Zhu, Y.; Cheng, L.; Anderson, B.; Zhao, X.; Wang, D.; Ding, A. Review on utilization of biochar for metal-contaminated soil and sediment remediation. J. Environ. Sci. 2018, 63, 156-173. [CrossRef]

14. Zhao, Z.; Jiang, G.; Mao, R. Effects of particle sizes of rock phosphate on immobilizing heavy metals in lead zinc mine soils. J. Soil Sci. Plant Nutr. 2014, 14, 258-266. [CrossRef]

15. Kulikowska, D.; Gusiatin, Z.M.; Bułkowska, K.; Klik, B. Feasibility of using humic substances from compost to remove heavy metals $(\mathrm{Cd}, \mathrm{Cu}, \mathrm{Ni}, \mathrm{Pb}, \mathrm{Zn})$ from contaminated soil aged for different periods of time. J. Hazard. Mater. 2015, 300, 882-891. [CrossRef]

16. Leelarungroj, K.; Likitlersuang, S.; Chompoorat, T. Leaching mechanisms of heavy metals from fly ash stabilised soils. Waste Manag. Res. 2018, 36, 616-623. [CrossRef]

17. Mavroulidou, M. Use of waste paper sludge ash as a calcium-based stabiliser for clay soils. Waste Manag. Res. 2018, 36, 1066-1072. [CrossRef] [PubMed]

18. Oprčkal, P.; Mladenovič, A.; Zupančič, N.; Ščančar, J.; Milačič, R.; Zalar Serjun, V. Remediation of contaminated soil by red mud and paper-ash. J. Clean. Prod. 2020, 256, 120440. [CrossRef]

19. Cappai, G.; Cara, S.; Muntoni, A.; Piredda, M. Application of accelerated carbonation on MSW combustion APC residues for metal immobilization and CO2 sequestration. J. Hazard. Mater. 2012, 207-208, 159-164. [CrossRef] [PubMed]

20. European Parliament and of the Council. EN 1744-3: Tests for Chemical Properties of Aggregates Part 3: Preparation of Eluates by Leaching of Aggregates; Slovinsky Institute of Standardization: Ljubljana, Slovenia, 2002.

21. Zhang, H. Probing into the speciation of trace metals and research methods, in Behaviors of trace metals in environment. In Behaviors of Trace Metals in Environment; Springer Nature: Singapore, 2020; pp. 299-342. [CrossRef]

22. Okoro, H.K.; Fatoki1, O.S.; Adekola, F.A.; Ximba, B.J.; Snyman, R.G. A review of sequential extraction procedures for heavy metals speciation in soil and sediments. Open Acc. Sci. Rep. 2012, 1, 1-9. [CrossRef]

23. Rodgers, K.J.; Hursthouse, A.; Cuthbert, S. The potential of sequential extraction in the characterisation and management of wastes from steel processing: A prospective review. Int. J. Environ. Res. Public Health 2015, 12, 11724-11755. [CrossRef] [PubMed]

24. Tessier, A.; Campbell, P.G.C.; Bisson, M. Sequential extraction procedure for the speciation of particulate trace metals. Anal. Chem. 1979, 51, 844-851. [CrossRef]

25. Milačič, R.; Zuliani, T.; Ščančar, J. Environmental impact of toxic elements in red mud studied by fractionation and speciation procedures. Sci. Total Environ. 2012, 426, 359-365. [CrossRef] [PubMed]

26. Sakan, S.M.; Sakan, N.M.; Đorđević, D.S. Trace element study in Tisa River and Danube alluvial sediment in Serbia. Int. J. Sed. Res. 2013, 28, 234-245. [CrossRef]

27. Sungurac, A.; Soylakb, M.; Ozcana, H. Investigation of heavy metal mobility and availability by the BCR sequential extraction procedure: Relationship between soil properties and heavy metals availability. Chem. Spec. Bioavail. 2014, 26, 219-230. [CrossRef]

28. Wei, J.; Duan, M.; Li, Y.; Nwankwegu, A.S.; Ji, Y.; Zhang, J. Concentration and pollution assessment of heavy metals within surface sediments of the Raohe Basin, China. Sci. Rep. 2019, 9, 13100. [CrossRef] [PubMed]

29. Ščančar, J.; Milačič, R.; Burica, O.; Stražar, M. Water and acetic acid leachable Cd, Cr, Cu, Fe, Ni, Pb and Zn in lime-treated sewage sludge. Ann. Chim. 2001, 91, 375-379.

30. Janoš, P.; Vávrová, J.; Herzogová, L.; Pilařová, V. Effects of inorganic and organic amendments on the mobility (leachability) of heavy metals in contaminated soil: A sequential extraction study. Geoderma 2010, 159, 335-341. [CrossRef]

31. Ashrafi, M.; Mohamad, S.; Yusoff, I.; Hamid, F.S. Immobilization of Pb, Cd, and $\mathrm{Zn}$ in a contaminated soil using eggshell and banana stem amendments: Metal leachability and a sequential extraction study. Environ. Sci. Pollut. Res. 2015, 22, 223-230. [CrossRef]

32. Wang, L.; Cho, D.-W.; Tsanga, D.C.W.; Caoc, X.; Houd, D.; Shend, Z.; Alessie, D.S.; Okf, Y.S.; Poon, C.S. Green remediation of $\mathrm{As}$ and $\mathrm{Pb}$ contaminated soil using cement-free clay based stabilization/solidification. Environ. Internet 2019, 126, 336-345. [CrossRef] 
33. Moretti, L.; Natali, S.; Tiberi, A.; D'Andrea, A. Proposal for a methodology based on XRD and SEM-EDS to proposal for a methodology based on XRD and SEM-EDS to monitor effects of lime-treatment on clayey soils. Appl. Sci. 2020, 10, 2569. [CrossRef]

34. Fazle Bari, A.S.M.; Lamb, D.; Choppala, G.; Bolan, N.; Seshadri, B.; Rahman, A.; Rahman, M.M. Geochemical fractionation and mineralogy of metal(loid)s in abandoned mine soils: Insights into arsenic behaviour and implications to remediation. J. Hazard. Mater. 2020, 399, 123029. [CrossRef]

35. Nejad, Z.D.; Jung, M.C. The effects of biochar and inorganic amendments on soil remediation in the presence of hyperaccumulator plant. Int. J. Energy Environ. Eng. 2017, 8, 317-329. [CrossRef]

36. Vidmar, J.; Zuliani, T.; Novak, P.; Drinčić, A.; Ščančar, J.; Milačič, R. Elements in water, suspended particulate matter and sediments of the Sava River. J. Soils Sed. 2017, 17, 1917-1927. [CrossRef]

37. Official Gazette of Republic Slovenia, Decree on Waste Landfill, Nos. 2020, 10/14, 54/15, 36/16, 37/18 and 129/20. Available online: https:/ / www.ecolex.org/details/legislation/decree-on-the-landfill-of-waste-lex-faoc130542/ (accessed on 16 November 2021).

38. Official Gazette of EU. Directive (EU) 2018/851 of the European Parliament and of the Council of 30 May 2018 Amending Directive 2008/98/EC on Waste (2018). Available online: https:/ / eur-lex.europa.eu/legal-content/EN/TXT/?uri=celex\%3A32018L0851 (accessed on 16 November 2021).

39. IUPAC-NIST Solubility Database, Version 1.1 NIST Standard Reference Database 106 Last Update to Data Content. 2012. Available online: https:/ / srdata.nist.gov/solubility / (accessed on 16 November 2021). [CrossRef] 